\title{
Necropolítica, poder e significados da pandemia do coronavírus: uma abordagem antropológica
}

\section{Necropolitics, power and meanings of the coronavirus pandemic: an anthropological approach}

\section{Necropolítica, poder y significados de la pandemia de coronavirus: un enfoque antropológico}

\author{
iD Jaqueline Ferreira \\ Universidade Federal do Rio de Janeiro, Rio de Janeiro, Rio de Janeiro, Brasil \\ jaquetf@iesc.ufrj.br
}

Resumo: O ano de 2020 foi marcado pela pandemia do coronavírus. O Brasil, país particularmente atingido pela doença, figura como péssimo exemplo na cena mundial graças ao número elevado de contaminados e mortos em consequência do negacionismo e da falta de programas e políticas direcionadas à prevenção e ao combate da doença. Este artigo, por meio de análise da literatura, reportagens de mídia e postagens de redes sociais, pretende refletir, em uma perspectiva antropológica, sobre o contexto brasileiro diante da pandemia sob dois registros: o impacto das respostas governamentais relacionadas com questões ideológicas pautadas por uma necropolítica; o fato de que o isolamento e a quarentena têm gerado grande impacto na sociedade dada a mudança de rotinas. Assim, busca-se analisar os significados simbólicos que a doença produz em relação às mudanças de hábitos e comportamentos, sobretudo no que se refere ao uso de máscaras e às práticas de desinfecção dos ambientes e objetos.

Palavras-chave: Pandemia. Coronavírus. Necropolítica. Poder. Antropologia.

Abstract: The year 2020 was marked by the coronavirus pandemic. Brazil, a country particularly affected by the disease, is a terrible example 
on the world stage thanks to the high number of contaminated and dead people as a result of denialism and lack of programs and policies aimed at preventing and fighting the disease. This article, through literature analysis, media reports, and posts on the social media, aims to think through the Brazilian context by taking an anthropological perspective in face of the pandemic under two registers: the first is about the impact of government responses related to ideological issues based on necropolitics; the second concerns the fact that isolation and quarantine have had a major impact on society due to routine changes. Thus, the study seeks to analyze the symbolic meanings produced by the disease in relation to changes in habits and behaviors, especially with regard to the use of masks and practices for disinfecting environments and objects.

Keywords: Pandemic. Coronavirus. Necropolitics. Power. Anthropology.

Resumen: El año 2020 estuvo marcado por la pandemia del coronavirus. Brasil, país particularmente afectado por la enfermedad, es un pésimo ejemplo en la escena mundial gracias al elevado número de contaminados y muertos resultante del negacionismo y de la falta de programas y políticas dirigidos a prevenir y combatir la enfermedad. Este artículo, a través de análisis de la literatura, informes de los medios de comunicación y publicaciones en redes sociales, se propone reflexionar desde una perspectiva antropológica acerca del contexto brasileño frente a la pandemia bajo dos registros: el primero es sobre el impacto de las respuestas gubernamentales relacionadas con cuestiones ideológicas guiadas por una necropolítica; el segundo se refiere al hecho de que el aislamiento y la cuarentena han generado un gran impacto en la sociedad debido al cambio de rutinas. Así, se busca analizar los significados simbólicos que produce la enfermedad en relación a los cambios de hábitos y comportamientos, sobre todo en lo que se refiere al uso de máscaras y a las prácticas de desinfección de los ambientes y objetos.

Palabras clave: Pandemia. Coronavirus. Necropolítica. Poder. Antropología.

Data de recebimento: 20/10/2020

Data de aprovação: 25/02/2021 


\section{Necropolítica, Poder e Significados da pandemia do co- ronavírus: uma abordagem antropológica}

O ano de 2020 foi marcado pela pandemia de coronavírus que assolou o planeta. A doença do coronavírus (Covid-19) é uma doença infecciosa causada por um coronavírus recém-descoberto e com alto grau de contagiosidade. Ele é transmitido por gotículas de saliva expelidas pela tosse, espirro ou exalação de uma pessoa infectada. Também é descrito que o vírus rapidamente se deposita em superfícies e pisos, e que o contato com eles pode levar igualmente à infecção e causar desde resfriados comuns a pneumonias graves.

O local da primeira contaminação foi a cidade de Wuhan na China, mas por causa da globalização houve a rápida disseminação pelo planeta e a infecção tornou-se uma grave ameaça global. Diante desse rápido aumento do número de casos no mundo, a Organização Mundial da Saúde (OMS) declarou a existência da pandemia pelo coronavírus em 11 de março de 2020 com mais de 118 mil casos em 114 países e 4,2 mil óbitos (LIRA E SILVA et al., 2020).

O fenômeno, que a princípio surpreendeu a comunidade científica, profissionais de saúde e dirigentes de diferentes países, gerou uma grande mobilização para a elucidação do vírus e suas consequências no organismo. Grande conhecimento sobre o coronavírus já foi adquirido, todavia ainda há muitos aspectos incertos, como, por exemplo, se as crianças são as principais transmissoras, qual o tempo de imunidade e a extensão das sequelas que ele provoca. Ainda há muito mistério envolvendo a síndrome. As medidas de segurança propagadas desde então têm sido o isolamento de casos, isolamento social, rastreamento social e a proteção dos profissionais de saúde. As dificuldades de organização e preparação dos profissionais de saúde fazem destes a maior fonte de propagação do vírus. Por outro lado, o isolamento e a quarentena têm gerado grande impacto na sociedade dada a 
Necropolítica, poder e significados da pandemia do coronavírus: uma abordagem antropológica Jaqueline Ferreira

mudança de rotinas, o afastamento do trabalho que causou grande desemprego, a crise econômica e o aumento da desigualdade social. Aliado a isso, há tendência de agravamento de problemas psicológicos e mentais em indivíduos vulneráveis e o aumento da violência doméstica.

O Brasil, país particularmente atingido pela síndrome, tem figurado como péssimo exemplo na cena mundial graças ao número elevado de contaminados e mortos, suas respostas negacionistas e à falta de programas e políticas direcionados para a prevenção e combate à doença. Nessa trama, as dimensões que tomam conta da pandemia dizem respeito ao impacto dessas respostas governamentais e às representações simbólicas que elas adquirem nas populações atingidas.

Assim, o objetivo deste artigo, embasado em reportagens da mídia e postagens de redes sociais, é analisar a doença da Covid-19 como o entrecruzamento entre ciência, políticas públicas e simbologias. Para isso, o arsenal teórico das ciências sociais, especificamente o da antropologia, é importante para o entendimento da cena atual (MALUF, 2020; ANSELMO, 2020). O primeiro caso de Covid-19 no Brasil, em 26 de fevereiro de 2020, foi após a confirmação de um homem de 61 anos que retornou da Itália e testou positivo para o vírus. Desde então confirmaram-se mais casos, alguns inclusive reportando a janeiro do mesmo ano (AGÊNCIA BRASIL, 2020). A partir desse momento, seguindo a dinâmica do desenvolvimento da doença, da pesquisa científica, da resposta governamental e do impacto na sociedade com seus desdobramentos de aceitação ou resistência, houve uma produção de sentidos sobre a pandemia expressa nas reportagens de mídia e redes sociais.

Os dados foram tratados pela análise de conteúdo na modalidade temática (MINAYO, 2010a; 2010b). A análise temática de conteúdo tem valor científico na medida em que procura se diferenciar das análises meramente intuitivas, pois segue regras partindo de uma descrição do conteúdo expresso das manifestações partindo, em seguida, para a análise mais aprofundada, realizando a inter- 
Necropolítica, poder e significados da pandemia do coronavírus: uma abordagem antropológica Jaqueline Ferreira

pretação dos conteúdos semânticos com conceitos sociológicos e procurando ir além dos significados manifestos (OLIVEIRA, 2008). Os dados aqui coletados referem-se a essas fontes, datando de fevereiro de 2020 até outubro de 2020. Eles foram colocados em uma tabela com o link, data e resumo do assunto. Na sequência foram agrupados segundo os temas para a sua interpretação. Interpretação esta que consistiu nas seguintes fases: exploração do material com diversas leituras de diferentes fontes, a partir das quais emergiram temas representativos e que foram agrupados por semelhança ou divergência; análise à luz de uma bibliografia socioantropológica.

Segundo a perspectiva antropológica, particularmente a antropologia da saúde, a doença não é um evento puramente biológico, mas abrange todos os aspectos da vida social do indivíduo e revela aspectos emblemáticos da sociedade (ALVES; MINAYO, 1994; LINDERBAUM; LOCK, 1993). De acordo com Claudine Herlizch: "Por meio da saúde e da doença, temos portanto acesso à imagem da sociedade, de suas 'imposições', tais como o indivíduo as vive. Englobada nesta imagem a doença adquire uma significação" (HERLIZCH, 1982, p. 177). Essa perspectiva é assumida neste texto.

A questão do poder, que perpassa as análises aqui apresentadas, parte de Michel Foucault. Para o autor, o corpo é objeto central da política, não no sentido do corpo ser um objeto sobre o qual o poder age, mas a própria fabricação da ação política que o coloca em funcionamento, define seus modos de reprodução e dispõe das modalidades de discurso sobre ele. Segundo o autor, é possível analisar historicamente as diferentes técnicas pelas quais o poder gerencia a vida e a morte das populações. Para isso ele utiliza a noção de "biopolítica", estabelecendo essa relação entre o poder e o corpo social na modernidade. Segundo Foucault, as técnicas governamentais biopolíticas se capilarizam em uma rede de poder que se estende em todos os meandros da vida social, incluindo todas as suas formas classificatórias, até penetrar no corpo individual (FOUCAULT, 1975, 1976). Mais tarde essa noção 
Necropolítica, poder e significados da pandemia do coronavírus: uma abordagem antropológica Jaqueline Ferreira

vai ser recuperada por Achille Mbembe para criar o conceito de necropolítica, como veremos mais adiante.

A antropóloga Emily Martin, em sua obra Flexible Bodies (1994), analisa aspectos importantes sobre a imunidade e política em relação à poliemielite e AIDS nos EUA que nos ajudam a pensar sobre a atual pandemia do coronavírus. Segundo a autora, a imunidade corporal não é um simples evento biológico, mas sim é construída coletivamente por elementos sociais e políticos que produzem exclusão, estigma, vida ou morte. Assim, se pensarmos a pandemia do Covid-19 sob o prisma de Michel Foucault, Emily Martin e Achille Mbembe, pode-se inferir que os vírus que se materializam no corpo individual são determinados pela gestão da vida e da morte das populações em determinado período. Nesse sentido, as políticas de imunização podem assumir um caráter violento pela radicalização das técnicas biopolíticas. Assim, uma epidemia coloca em cena os significados que a sociedade atribui para a classificação de puro/impuro, público/privado, vida/morte de forma a atualizar a gestão biopolítica e necropolítica que sempre atuaram no seu território.

Dessa forma, dois grandes registros foram escolhidos como eixo organizador para essa análise: ideológicos-políticos e simbólicos. As temáticas específicas foram então organizadas nessa perspectiva.

\section{A pandemia sob as lentes ideológicas e políticas: necropolítica em ação}

Se na cena internacional o reconhecimento oficial da doença foi quase imediato e as pesquisas puderam se realizar de maneira independente do poder público, aqui, no Brasil, houve dificuldade das autoridades reconhecerem a gravidade da situação e implantarem políticas coerentes. Melhor dizendo, no Brasil houve um negacionismo por parte da gestão pública desde o início. Não houve adoção de medidas nacionais de contenção do vírus, 
Necropolítica, poder e significados da pandemia do coronavírus: uma abordagem antropológica Jaqueline Ferreira

deixando estas a cargo dos governos estaduais e municipais. Em muitos momentos, o próprio presidente assumiu posturas que iam de encontro ao recomendado, provocando aglomeração de pessoas, aperto de mãos e sem uso de máscaras. Tudo isso contribui para levar a população a um sentimento de dúvidas e incertezas diante do preconizado pelos médicos e órgãos competentes como a Organização Mundial da Saúde (OMS). O fato do vírus ter origem na China levou algumas autoridades do governo a levantar a hipótese de uma conspiração comunista com o objetivo de beneficiar aquele país economicamente. Nesse sentido, "comunista" passou a ser uma categoria de acusação, atualizando a polaridade esquerda $\mathrm{x}$ direita da última eleição à presidência da república. Como consequência, eleitores do então presidente Jair Bolsonaro negavam a doença e/ou a sua gravidade, enquanto seus opositores combatiam veementemente suas atitudes. Segundo Eliane Anselmo:

Tal narrativa se construiu em cima da falsa ideia de que a Covid-19 é apenas uma 'gripezinha' inventava e reproduzida pela China com finalidades diversas, entre elas comerciais e econômicas. Ao negar a seriedade sustentada pelas mais diversas autoridades médicas e científicas, tal postura construiu uma noção paralela de mundo, onde os culpados são sempre os outros, particularmente os outros culturalmente diferentes. Assim, se torna fácil sempre projetar uma determinada culpa nos outros, para se isentar das responsabilidades que lhes cabem enquanto gestores públicos. Isso acontece no Brasil e o atual presidente da república brasileira reproduz exatamente essa postura narrativa, transformada em ação, ou em falta de ação (ANSELMO, 2020, p. 168).

Órgãos oficiais relatam como as estatísticas deixam a desejar. As notificações da doença são falhas pela falta de testes, diagnósticos não realizados em linhas de frente dos serviços de saúde, indivíduos que adoecem e não procuram assistência (NOIS, 2020). Por outro lado, veículos de imprensa denunciam a ocultação de 
Necropolítica, poder e significados da pandemia do coronavírus: uma abordagem antropológica Jaqueline Ferreira

dados oficiais de forma proposital por parte do governo federal a fim de amenizar o impacto local da doença. A mídia, nesse aspecto, tem exercido bastante pressão no governo a ponto de ter a sua liberdade de expressão cerceada pelo mesmo (VARGAS, 2020).

Ainda que a infecção pelo coronavírus tenha sido negada pelo governo federal no primeiro momento, não impediu que os doentes tenham sido tratados pelos serviços de saúde locais. Isso acabou contribuindo na isenção da responsabilidade do Ministério da Saúde para responder ao problema com programas e políticas eficazes. Outrossim, esse negacionismo foi acompanhado algumas vezes de violência, como, por exemplo, quando o presidente da república incentivou a invasão de hospitais de campanha (LEMOS, 2020).

O silêncio sobre a pandemia se sustenta não só nas atitudes explícitas de negação do governo, mas também nos baixos níveis de alfabetização do país, nas dificuldades de acesso à internet por parte da população e na vida precária dos moradores de rua ou das populações vivendo em áreas de difícil acesso, como na região amazônica, por exemplo (VIEIRA, 2020). Dessa forma, como afirma Eliane Anselmo, “... informações falsas e manipuladoras mantêm um padrão determinado de circulação, em muitos casos, com mais rapidez do que o próprio vírus e também muito mais nocivo do que ele próprio" (ANSELMO, 2020, p. 171)

Por outro lado, a assistência frequentemente escancarou as desigualdades sociais e raciais no país no que diz respeito ao acesso aos serviços de saúde. Há índices que apontam que pessoas que se autodeclararam como brancas acessaram consideravelmente mais leitos de UTI ou ventilação mecânica em relação às pretas, pardas e amarelas (ALVES DOS SANTOS, 2020). Outro ponto é o total abandono das populações indígenas e quilombolas, vê-se grande parte de indivíduos desses grupos morrerem (OLIVEIRA et al., 2020). Ao mesmo tempo, com a pandemia, órgãos ambientais e indigenistas estão funcionando mais restritamente e oportunizando que grileiros, madeireiros e garimpeiros invadam e expulsem os indígenas de seus territórios, tornando-os, inclusive, mais vul- 
Necropolítica, poder e significados da pandemia do coronavírus: uma abordagem antropológica Jaqueline Ferreira

neráveis ao vírus. É impossível esquecer a fala do ministro do meio ambiente, muito divulgada pelos meios de comunicação, sobre "aproveitar o momento para passar a boiada" (expressão coloquial que significa facilitar a passagem de algo), para flexibilizar normas ambientais (NICOLAV, 2020). De fato, uma dessas mudanças foi o desmatamento, a regularização de propriedades rurais em terras indígenas, permitindo sua invasão e comercialização.

Outro ponto igualmente relevante foi a elevação dos índices de mortalidade materna no país. Em uma publicação recente no International Journey of Ginecology and Obstetrics, com base em dados disponíveis pelo sistema SIVEP Gripe do Ministério da Saúde, pesquisadoras apontam que a taxa de mortalidade por Covid-19 entre as gestantes brasileiras é de 12,7\% (TAKEMOTO et al., 2020). Até junho, em outros países, a taxa encontrada seria 3,5 vezes menor (FEBRASGO, 2020).

Todos esses fatos demonstram que o advento da pandemia no Brasil evidencia aspectos da sociedade brasileira em que o comportamento adotado pelo Estado provoca dinâmicas de diferenciação. Assim, o surgimento da Covid-19 evidencia que não se trata apenas de um evento puramente biológico, mas também político, que, por sua vez, revela as desigualdades estruturais no país em que populações pobres, negras e periféricas são negligenciadas em uma perspectiva que Achille Mbembe (2016) denomina de necropolítica.

Segundo o autor, sob o prisma da necropolítica, alguns corpos deixam de ser reconhecidos como sujeitos de políticas de Estado. O Estado assume, assim, o direito de deixar viver uns em detrimento de outros ou de fazer morrer ou morrer lentamente em detrimento de algo maior, de um bem supostamente coletivo (MBEMBE, 2016).

Mbembe baseia-se no conceito de necropolítica a partir de noção de biopolítica de Foucault, em que os biopoderes que administram e controlam a população ocupam-se da gestão da saúde na medida em que passam a ser preocupações políticas. 
Necropolítica, poder e significados da pandemia do coronavírus: uma abordagem antropológica Jaqueline Ferreira

Mbembe vai além do conceito de Foucault. Para ele, Foucault não dá conta das relações contemporâneas de racismo, perseguição e conflitos que fortalecem políticas de morte, a necropolítica. Embora Mbembe seja um grande estudioso sobre o racismo e as políticas coloniais, seu conceito não se restringe aos negros, mas sim a todas as minorias, pois quanto mais vulnerável for o grupo maior o desequilíbrio entre o poder da vida e da morte sobre ele.

De acordo com Mbembe, no mundo contemporâneo existem estruturas com o objetivo de provocar a destruição de alguns grupos. Essas estruturas são formas contemporâneas de vidas sujeitas ao poder da morte e seus respectivos "mundos de morte" - formas de existência social em que vastas populações são submetidas às condições de vida que os conferem um status de "mortos-vivos". Para o autor, o Estado é quem deve estabelecer os limites entre direitos, violência e morte. A necropolítica se instaura quando o Estado não estabelece essa fronteira e usa seu poder e discurso para criar zonas de morte.

$\mathrm{Na}$ perspectiva necropolítica alguns discursos podem promover conflitos entre grupos, instaurando medo, insegurança e precariedade, e para resolver certas situações pode-se estabelecer parâmetros de aceitabilidade para tirar vidas, os corpos matáveis. Isso pode ser explícito com o uso ilegítimo da força policial, guerras e genocídios, levando a crises humanitárias ou quando difundemse estruturas racistas e patriarcais que, direta ou indiretamente, produzem desigualdade.

Nessa perspectiva, o negacionismo também figura como uma forma de necropolítica. Após a recusa oficial do reconhecimento da dimensão da doença, houve a neutralização dos enunciados científicos e discursos técnicos no primeiro momento da pandemia. Um exemplo foi a ampla divulgação do uso de máscaras pela comunidade científica, que foi negligenciada inúmeras vezes por dirigentes e principalmente pelo próprio presidente da república. Assim, essa dimensão do negacionismo abarcou a negação da ciência propriamente dita, gerando desinformação e conflitos. o exemplo típico foi o uso da cloroquina. Apesar de nenhuma 
Necropolítica, poder e significados da pandemia do coronavírus: uma abordagem antropológica Jaqueline Ferreira

evidência científica, essa medicação foi preconizada por setores da administração pública como forma de combate à Covid-19. Tratava-se de um produto produzido pelos laboratórios do Exército brasileiro, o que, segundo Alves da Silva (2020), dá um "certo tom de esmagadora sabedoria nacional" (p. 386). Decorrente dessa preconização houve a compra massiva da medicação pelas farmácias de todo o país com o subsequente desabastecimento dos usuários que realmente necessitavam dessa medicação. Segundo o autor:

[...] a cloroquina adquiriu o poder de engendrar crises políticas, mobilizando economia (tendo em vista o crescente aumento de preços de seus componentes), política e administração de questões relativas ao enfrentamento da pandemia. Essas constantes disputas se dão concomitantes a um conjunto de estudos clínicos que apontam a ineficácia da cloroquina no combate ao Covid-19 e às recomendações da Organização Mundial da Saúde do não uso dessa substância (ALVES DA SILVA, 2020, p. 386).

Tal fato ilustra como critérios diferentes são aplicados segundo o contexto no qual a evidência científica é analisada. Faz parte do campo científico a convivência com a ambiguidade e conflitos diante de resultados novos (LATOUR, 1990; KUHN, 2006). Isso é mais do que verdadeiro no âmbito do coronavírus em relação às incertezas que cercaram o evento desde o início e que persistem até hoje. Nas esferas políticas essas incertezas e ambiguidades podem levar a disputas de cunho moral. É o que Alves da Silva (2020) chama a atenção quando o "cidadão de bem" reivindica a imagem de trabalhador que deseja retomar a economia ao se manifestar contra o isolamento e à parada de atividade econômica dos municípios. Dessa forma, na disputa entre a esfera científica e a política, ganha importância a ideia de produtividade da vida normal e dos "cidadãos de bem que lutam apenas e somente por permissão para trabalhar" (p. 386). 
Necropolítica, poder e significados da pandemia do coronavírus: uma abordagem antropológica Jaqueline Ferreira

Conforme já referido no tópico anterior, a pandemia repercutiu de forma diferente para os diferentes grupos sociais. As experiências de isolamento são diferentes para os indivíduos de classe média e para os pobres. Para estes, trabalhadores informais e autônomos, não existe a escolha de "ficar em casa", tornando-os especialmente vulneráveis e reforçando as desigualdades sociais. A negação da doença também tem a ver com o medo do isolamento, de perder o emprego, do medo da morte, conforme será abordado no próximo tópico.

A categorização dos idosos como "grupo de risco" é bastante problemática, pois tende a estereotipá-los, estigmatizando-os e tonando-os ainda mais vulneráveis. (COSTA DOURADO, 2020). Igualmente, transmite a falsa sensação de segurança para o restante dos indivíduos, o que os desobriga do isolamento. Por outro lado, o isolamento coloca a responsabilidade da doença sobre os indivíduos, o que não raro confere constrangimento e medo de acusação por parte das pessoas que contraíram o vírus, conforme o relato de Cláudia Rezende (2020). Aliada às dificuldades concretas, soma-se a resistência ao isolamento e ao uso de máscaras sob o argumento de "atentado à liberdade individual", conforme veremos adiante.

O fato é que as doenças transmissíveis devem ser compreendidas dentro de seu contexto social porque coloca em discussão a dinâmica das relações sociais existentes. É a respeito disso que pretendo refletir a seguir.

\section{A pandemia em relação aos aspectos sociais e simbólicos}

As doenças infecciosas sempre mobilizaram inúmeras representações sociais sobre o contágio. São representações que compreendem valores, crenças e o próprio saber científico. A análise dos significados culturais e históricos, construída para designar as doenças, nos possibilita entender os valores, os símbolos e as regras da sociedade. Não foi diferente com a pandemia pelo 
Necropolítica, poder e significados da pandemia do coronavírus: uma abordagem antropológica Jaqueline Ferreira

coronavírus. Desde o início ela articulou diferentes modalidades de representações nas populações atingidas. São representações que se ancoram no conhecimento do senso comum transmitido pela mídia e nas divulgações científicas, ancorados em valores e juízos morais dos grupos sociais.

De acordo com Martins (1997), a ideia de contágio, desde os tempos remotos, remete ao contato com alguém ou algo que tocamos. O risco de transmissão e os mecanismos através dos quais ocorre o contágio contribuem para a construção social da doença e conduzem, inevitavelmente, a comportamentos que tendem a separar o enfermo da sociedade, por meio da rejeição ou do isolamento. No que se refere especificamente à Covid-19, no ano de 2020, em que as intervenções farmacêuticas e vacinas estavam sendo pesquisadas, o que havia de concreto é que a prática da quarentena e do isolamento social são as estratégias mais adequadas para mitigar a disseminação da doença, minimizar a sobrecarga dos sistemas de saúde e reduzir infecções e mortes (FERGUSON et al., 2020).

\section{O medo e a hostilidade diante do desconhecido}

Os primeiros registros da infecção pelo coronavírus tratavamna como uma infecção exótica e distante localizada na China. O foco original seria um mercado da cidade de Wuhan, onde se misturavam alimentos e animais em gaiolas e sujeira. Uma hipótese inicial muito discutida é que o coronavírus teria "migrado" dos morcegos para o ser humano. Essa ideia provocou rapidamente a circulação de notícias de que chineses "comem morcegos" e assim teriam disseminado a doença. Esse discursos, claramente etnocêntricos, "viralizaram" nas redes sociais propagando a estigmatização e reações xenofóbicas ao povo chinês. Houve um caso amplamente relatado na imprensa de impedimento de uso de elevadores por chineses em um prédio comercial em São Paulo (FÓRUM, 2020). Tal fato pode ser interpretado à luz de posturas etnocêntricas, 
Necropolítica, poder e significados da pandemia do coronavírus: uma abordagem antropológica Jaqueline Ferreira

em que o choque cultural com o Outro, exótico e diferente, nos provoca a impossibilidade de lidar com a diferença no plano intelectual e com o medo e a hostilidade no plano emocional. Não esquecendo também que a observação de culturas alheias se faz segundo pontos de vista definidos pela cultura do observador, ou seja, os critérios de avaliação são também culturais. Dessa forma, ao mesmo tempo que se designa a principal população atingida, procura-se responsabilizá-la pela sua disseminação pelo mundo e estigmatizá-la. O Outro é esse que nos contamina e nos coloca em reclusão e evitação de todas as possíveis formas de contágio.

De acordo com Maria Cláudia Coelho (2020), há muito medo que circunda os perigos do contágio diante das dúvidas sobre métodos e eficácia de desinfecção. Por outro lado, segundo a autora, não há muitos meios no espaço público para o debate sobre os aspectos mais sensíveis e dolorosos que a doença suscita, como as angústias do isolamento ou a morte dolorosa sob respiradores em Unidades de Tratamentos Intensivos. Nessa linha de raciocínio, Carla Rodrigues chama a atenção para a negação ao luto pela impossibilidade de velamento dos mortos. Todos esses aspectos povoam as representações coletivas diante do desconhecido. O medo da doença é consequência da incapacidade de compreendê-la ou aceitá-la. Enfim, a doença exige sempre uma necessidade de discurso, a necessidade de uma interpretação complexa e contínua da sociedade inteira (HERZLICH, 1984).

\section{Rituais de limpeza - o medo do contágio}

Uma das prerrogativas que os tempos de coronavírus trouxe foi o "lavem frequentemente as mãos e realizem desinfecção dos ambientes e objetos que entram em casa". Grande parte dos indivíduos das camadas médias assumiu essa postura. O perigo da infecção e o medo do contágio foi muito presente sobretudo nos primeiros tempos de pandemia. Relatos nas redes sociais sobre lavar alimentos e objetos que vêm da rua para casa com álcool, água sanitária, por exemplo, mostraram a amplitude desse temor. 
Necropolítica, poder e significados da pandemia do coronavírus: uma abordagem antropológica Jaqueline Ferreira
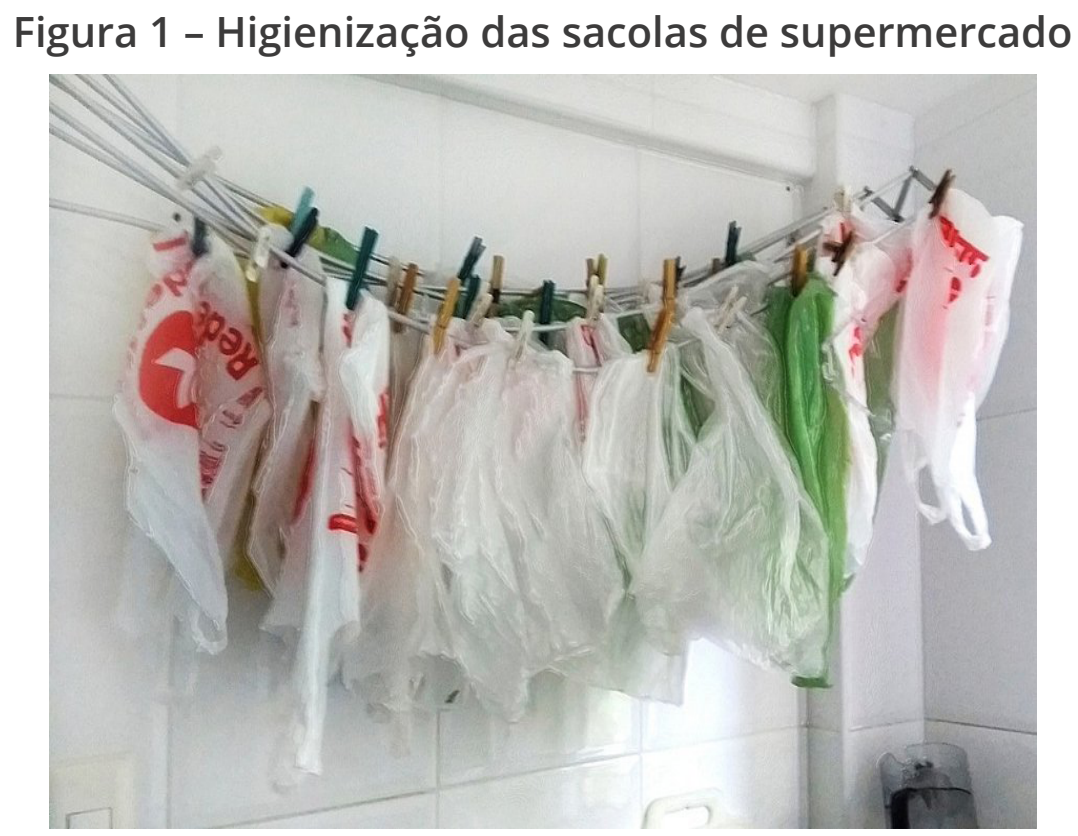

Fonte: Priscila Natividade (23 maio 2020).

Figura 2 - Higienização das compras de alimentos

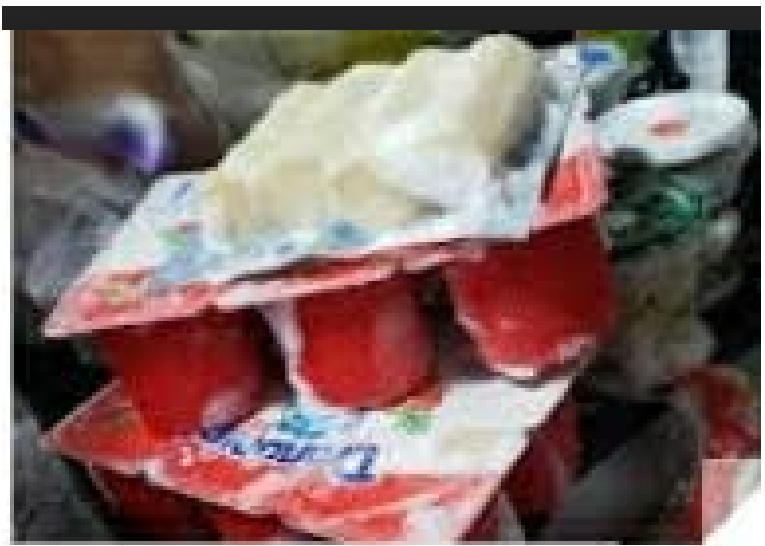

Fonte: Página Coronavírus Brasil - Facebook (07 maio 2020).

Figura 3 - Higienização das compras de alimentos

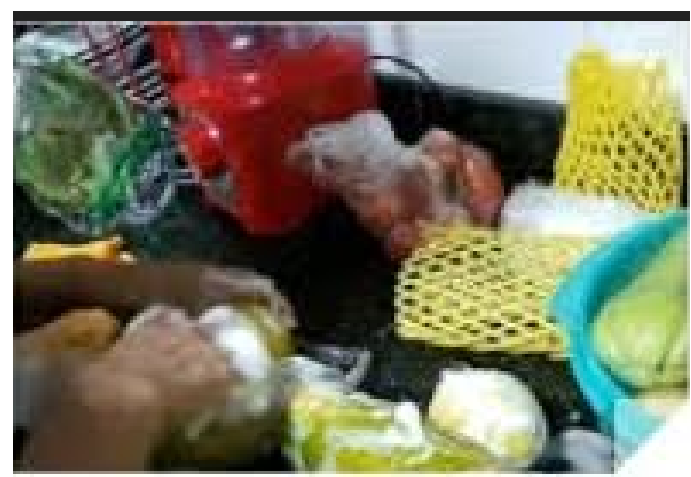

Fonte: Página Coronavírus Brasil - Facebook (07 maio 2020). 
Necropolítica, poder e significados da pandemia do coronavírus: uma abordagem antropológica Jaqueline Ferreira

Douglas (1981) demonstrou como em cada cultura, ocidental ou não, as ideias de contaminação e sujeira assumem configurações específicas. Na cultura ocidental, as noções de higiene e de transmissão de doenças são baseadas na teoria dos germes. No entanto, como explica a autora, toda a sujeira é um subproduto de uma organização e classificação da matéria: "A sujeira - a autora escreve - é essencialmente desordem [...], e os rituais de pureza e de impureza conferem uma certa unidade à nossa experiência." (DOUGLAS, 1981, p. 24). Essa referência nos remete à ideia de contaminação, em que duas categorias se tornam eminentes: o conceito de impureza e sua relação com um agente infeccioso, um animal ou objeto. A impureza que a autora menciona implica a ideia do que transcende margens e fronteiras. Podemos relacionar aqui a ideia da casa como o ambiente seguro, limpo, e tudo o que vem do exterior é o impuro e, portanto, perigoso. Para DaMatta (1997)), "casa" e "rua" não são somente espaços geográficos, mas categorias sociológicas que designam entidades morais e expressões culturais e são, portanto, "capazes de despertar emoções, reações, leis, orações, músicas e imagens esteticamente emolduradas e inspiradas" (p. 31).

Na rua a vergonha da desordem não é mais nossa, mas do Estado. Limpamos ritualmente a casa e sujamos a rua sem cerimônia ou pejo... Não somos efetivamente capazes de projetar a casa na rua de modo sistemático e coerente, a não ser quando recriamos no espaço público o mesmo ambiente caseiro e familiar (DAMATTA, 1997, p. 34).

De fato, a ideia de limpeza das impurezas e evitação do contágio falam mais do imaginário sobre a sociedade. Como bem relembra Georges Vigarello (1996), no século XIX as descobertas de Pasteur e Koch fizeram os médicos proporem banhos frequentes, lavagem dos ambientes, desinfecção das casas e rígidas quarentenas. Dessa forma, não se trata de noções embasadas simplesmente em bases científicas, mas também sobre uma imagem que a sociedade produz sobre si mesma e sobre os seus indivíduos. Assim, diante 
Necropolítica, poder e significados da pandemia do coronavírus: uma abordagem antropológica Jaqueline Ferreira

do invisível, o excesso de limpeza torna-se normal, como também o controle sobre si e sobre o outro em uma disciplinarização foucaultiana dos corpos (FOUCAULT, 1999). Como consideram Carvalho et al.: "Na ausência de ferramentas bioquímicas capazes de disciplinar a propagação do vírus, disciplinam-se os corpos. Distanciamentos, máscaras, lavagem demorada das mãos, álcool em gel 70\%, e assim por diante" (2020, p. 3).

\title{
As máscaras como mediação técnica
}

\begin{abstract}
“Manhã de terça feira. A pessoa que entrou em minha frente no mercado se negou a aceitar a borrifada de álcool em gel que o funcionário colocava nas mãos dos demais clientes. Um dos feirantes deixou o nariz para fora da máscara, talvez inspirado no presidente ou na ideia de uma mordaça, fiquei na dúvida. Pela janela de uma empresa de publicidade, vi que várias pessoas trabalhavam sem máscara: uma delas segurava sua máscara, que continuava presa a uma das orelhas, enquanto conversava com um colega. Pessoas caminhavam na rua com a máscara no queixo como se fosse um babeiro. Algumas pessoas corriam na Redenção sem máscara, como se ninguém se importasse com a respiração ofegante, frequentemente pela boca".

Mário Eugênio Sareta Pogglia (19 maio 2020).
\end{abstract}

Admite-se que o uso de máscaras pode contribuir para a conscientização da responsabilidade coletiva e pessoal no enfrentamento a doenças infecciosas. A aprendizagem do uso correto das máscaras pela população vem sendo amplamente divulgada pela mídia (GARCIA, 2020).

As redes sociais são pródigas em dar exemplos de mau uso ou da importância do uso e do uso correto, bem como de "denúncia" da recusa do seu uso, como ilustra a epígrafe desta seção no depoimento do antropólogo Mário Sareta e da antropóloga Gilse Rodrigues: "Tem muita gente usando máscara como uma espécie 
Necropolítica, poder e significados da pandemia do coronavírus: uma abordagem antropológica Jaqueline Ferreira

de patuá1, na bolsa, no bolso, pendurada na orelha, no pescoço" (2020). Apesar da ironia do post, a ideia da máscara como patuá, ou seja, um amuleto, implicaria a ideia de que o simples fato de portá-la garantiria a proteção a que ela se destina.

Nesse sentido, gostaria de lembrar a referência de mediação técnica de Bruno Latour. No texto On technical mediation philosophy, sociology, genealogy (1994), Latour apresenta essa noção em que o humano e o objeto técnico mudam a partir da nova relação nessa interação humano/objeto. O argumento de Latour é a recusa do determinismo da técnica sobre o humano e do humano sobre a técnica. Assim, o simples uso da máscara como impeditivo da infecção configuraria a predominância da técnica sobre o humano (determinismo tecnológico) e o mau uso colocaria os indivíduos em risco, com o poder exclusivo aos humanos (determinismo humanístico). Seguindo o argumento de Latour, defendo aqui que a máscara não passa de uma tecnologia mediadora, em que o objeto, o artefato, não implica ação em si, mas sua potencialidade em realizar a ação, que no caso só seria concretizada na sua confluência com o humano. Dessa forma, Latour defende que não há primazia do homem sobre o artefato ou vice-versa. Na mediação técnica entre humanos e máscaras, ambos formam um par dialógico em que as partes isoladas não contêm atributos do todo. Os significados de humanos e objetos existem não isolados, mas numa relação dialógica através da mediação.

O ato de vestir as máscaras pode ser compreendido em uma ampla gama de significados. Por exemplo, elas podem ser consideradas um facilitador das relações sociais, na medida em que nos possibilitam sair de casa, ir ao mercado, andar pelas ruas, pegar ônibus ou metrô. Por outro lado, nos lembra que devemos ter distância e evitar aglomerações, mas também podem criar formas alternativas de economia e solidariedade. Muitas pessoas começaram a produzir máscaras para vender nessa pandemia e as redes sociais não cansam de mostrar pessoas mascaradas em suas

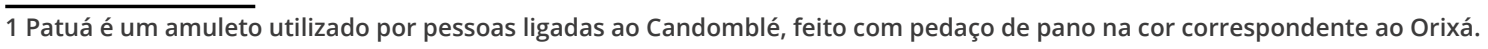


Necropolítica, poder e significados da pandemia do coronavírus: uma abordagem antropológica Jaqueline Ferreira

atividades de trabalho ou lazer, mostrando que nos importamos conosco e com os outros.

Da mesma forma, na relação com a saúde, salvo o uso pelos profissionais de saúde, o uso de máscara nos lembra continuamente que somos um paciente potencial. Também nos remete ao anonimato, a rostos sem nomes, à lembrança de que somos cidadãos comuns. Essas razões explicam por que vez ou outra encontramos reações negativas e até mesmo violentas de indivíduos que se negam a usar máscaras ao entrar em estabelecimentos. Foi o caso amplamente divulgado na mídia do casal que, ao ser interpelado por fiscais da vigilância sanitária sobre o uso de máscaras, reage com a fala: "Cidadão não, engenheiro civil, formado, melhor do que você!" (SOUZA; NASCIMENTO DE SOUZA, 2020). A fala é emblemática sobre as relações da sociedade brasileira. O casal aqui se recusa a ser "cidadão" comum, ilustrando da melhor forma a questão da cidadania num universo relacional do povo brasileiro em que o "você sabe com quem está falando?" foi exemplarmente destacado por Roberto DaMatta (1997).

\section{À guisa de conclusão: reflexões de uma antropóloga em isolamento}

Em outubro de 2020, no momento de escrita deste artigo, o Brasil contava com 151.747 óbitos pelo coronavírus (Template: Covid-19). Discutia-se a volta ou não às aulas presenciais. Professores estavam esgotados e inseguros diante das incertezas. Profissionais de saúde continuavam lutando diante de um sistema de saúde público cada vez mais fragilizado pelas políticas neoliberais. O "morra quem morrer" em prol da economia ilustrava a tragédia brasileira e o desprezo aberto à vida por parte dos dirigentes do país. Desconsiderava-se o valor de algumas vidas, os corpos com menos valor, os "corpos matáveis" que podem ser desconsiderados ou descartados afetando sempre as mesmas 
Necropolítica, poder e significados da pandemia do coronavírus: uma abordagem antropológica Jaqueline Ferreira

raças, os mesmos gêneros e as mesmas classes sociais, como bem nos mostra Mbembe (2016) em seu conceito de necropolítica.

Os anúncios de uma vacina trouxeram esperança que em médio prazo a vida volte ao normal ou ao "novo normal", como bem critica Jean Segatta (2020), que é uma noção que nos remete a uma naturalização dos processos de destruição do planeta, ou seja, a naturalização da necropolítica. Flávia Birolli escreve que em síntese:

A tragédia brasileira tem vários componentes. Neoliberalismo, autoritarismo, baixa capacidade de liderança política, rechaço pela ciência e um desprezo aberto pela vida compõem a ausência de respostas adequadas para os efeitos da pandemia. As inseguranças sanitárias e econômicas são vividas em um contexto no qual ataques à democracia se manifestam cada vez mais abertamente (BIROLI, 2020, p. 1).

No estudo político da pandemia, deve-se analisar o conjunto de dispositivos de poder nas suas dimensões mais institucionais e nas mais banais, na medida em que ela, a pandemia, coloca em evidência o poder nas suas mais variadas formas de expressão.

Nossas rotinas foram alteradas. A casa, lugar de refúgio e descanso para uns e lugar permeado de conflitos de classe, geracionais ou de gênero para outros, não é mais a mesma. $\mathrm{O}$ "ficar em casa" virou privilégio para aqueles que não têm dificuldades de acesso aos serviços como internet e nem problemas com a sua habitação. Por outro lado, a inversão da casa como espaço familiar, íntimo acolhedor, transformada em espaço de trabalho, espaço originalmente da rua (DAMATTA, 1997), desorganiza as dinâmicas familiares e os espaços individuais de refúgio. O home office frequentemente transformado em full time tem levado indivíduos à exaustão e afetado a saúde mental, sobretudo de professoras/os.

Falando em privilégios, acerca da ideia que chegou a circular de um vírus "democrático", que dada à sua alta contagiosidade poderia atingir a todos, logo se confirmou que não é bem assim, 
Necropolítica, poder e significados da pandemia do coronavírus: uma abordagem antropológica Jaqueline Ferreira

uma vez que a pandemia mostra que tem raça e classe social reforçando o que já dizia Rita Barata: as desigualdades sociais fazem mal à saúde (BARATA, 2009).

A Covid-19 nos convida a analisar as múltiplas interpretações que estão carregadas de significado e conteúdo moral. O medo do contágio, as ideias de impureza e o cuidado de si e dos outros são revisitados nesses tempos. Por outro lado, há a negação que lota as praias, onde os guarda-sóis coloridos contrastam com o branco dos hospitais e o cinza dos cemitérios super lotados. Uma negação que lembra que existe o sol e que é possível respirar sem máscaras. É uma tendência cultural em que para sobreviver psicologicamente em tempos pandêmicos, negamos a morte ostentando-nos imunes a ela. Essa naturalização deve-se ao aspecto rotineiro de dados estatísticos que foram mostrados continuamente pelo Jornal Nacional da Rede Globo. Mas também tem relação com a forma que o governo federal tem lidado com o enfrentamento da pandemia, o "e daí?" explicitado pelo presidente da república mostra que quem tem que morrer, morrerá mesmo.

Entretanto, em algum momento a pandemia vai arrefecer, através da vacina e de uma imunidade significativa, fazendo as taxas de contaminação e de mortes caírem. Esse momento há de vir paulatinamente e será integrado ao nosso cotidiano até ser assimilado. Os momentos de isolamento, o uso de máscaras, as práticas obsessivas de desinfecção hão de ficar no passado. No entanto, esse processo, que será às custas de muitas mortes, não poderá ser comemorado como uma vitória.

\section{Referências}

AGÊNCIA BRASIL. Covid-19: governo declara transmissão comunitária em todo o país. Disponível em: https://agenciabrasil.ebc. com.br/saude/noticia/2020. Acesso em: 30 abr. 2020.

ALVES, Paulo Cesar; MINAYO, Maria Cecília de Souza (Org.) Saúde e Doença: Um Olhar Antropológico. Rio de Janeiro: FIOCRUZ, 1994. 
Necropolítica, poder e significados da pandemia do coronavírus: uma abordagem antropológica Jaqueline Ferreira

ALVES DA SILVA, Wagner Guilherme. Cloroquina: um programa de Estado. Áltera, João Pessoa, v.1, n.10, p. 382-389, jan./jun. 2020.

ANSELMO, Eliane; CORREA GARCIA, José Wilson. RBSE Revista Brasileira de Sociologia da Emoção, v. 19, n. 55, p. 162-174, abril, 2020, Suplemento Especial.

BARATA, Rita B. Como e Por Que as Desigualdades Sociais Fazem Mal à Saúde. Rio de Janeiro: Editora Fiocruz, 2009. BIROLI, Flávia. A tragédia brasileira. ANPOCS. Boletim Ciências Sociais. n. 81, julho, 2020. Disponível em: http://anpocs.org/ index.php/publicacoes-sp056165036/boletim-cientistas-sociais/2412-boletim-cientistas-sociais-n-81. Acesso em: 10 out. 2020. CARVALHO, Mario et al. Metáforas de um vírus: reflexões sobre a subjetivação pandêmica. Psicol. Soc. vol. 32, p. 1-15, 2020.

COELHO, Maria Cláudia. Porcos-espinhos na pandemia ou a angústia do contágio. DILEMAS: Revista de Estudos de Conflito e Controle Social, Rio de Janeiro, p. 1-10, 2020.

COSTA DOURADO, Simone P. A pandemia do COVID-19 e a conversão dos idosos em grupos de risco. Cadernos de Campo, vol. 29, (suplemento), p.153-162. 2020

DOUGLAS, Mary. Pureza e Perigo. Rio de Janeiro: Edição 70, 1981.

DAMATTA, Roberto. Carnavais Malandros e Heróis: por uma sociologia do dilema brasileiro. Rio de Janeiro: Rocco, 1997.

DAMATTA, Roberto. A casa e a rua: espaço, cidadania, mulher e morte no Brasil. Rio de Janeiro: Rocco, 1997.

FEBRASGO. Nota oficial de alerta às mortes maternas associadas a covid-19, 2020. Disponível em: https://www.febrasgo.org. br/pt/noticias/item/1067-nota-oficial-de-alerta-as-mortes-maternas-associadas-a-covid-19. Acesso em: 19 set. 2020.

FERGUSON, Neil et al. Impact of non-pharmaceutical interventions (NPIs) to reduce Covid19 mortality and healthcare demand 2020. 
Necropolítica, poder e significados da pandemia do coronavírus: uma abordagem antropológica Jaqueline Ferreira

Imperial College Covid-19, Londres, p. 1-20, 2020. Disponível em: https://www.imperial.ac.uk/media/imperial-college/medicine/ mrc-gida/2020-03-16-COVID19-Report-9.pdf. Acesso em: 10 out. 2020.

FOUCAULT, Michel. A História da Sexualidade. A vontade de saber. Paris: Ed. Gallimard, 1976.

FOUCAULT, Michel. Vigiar a Punir. Paris: Ed. Gallimard, 1975. FOUCAULT, Michel. Em defesa da sociedade: Curso dado no Collège de France (1975-1976). São Paulo: Martins Fontes, 1999.

FÓRUM. Chineses são proibidos de usar elevador em prédio comercial de São Paulo. Porto Alegre, fev., 2020. Disponível em: https://revistaforum.com.br/brasil/chineses-sao-proibidos-de-usar-elevador-social-de-predio-comercial-em-são paulo/?fbclid=IwAR29aBgdFojJDknW0bXGnAJIXnzalGXXQ2zTuwdKpFAYITuEpBcXJVhfnw. Acesso em: 20 abr. 2020.

HERZLICH, Claudine. Perception et représentations des images, santé, corpos, handicaps. In: DESCHAMPS, Pierre (org). Conception, Mesure et Actions en Santé Publique. Colloque, v.104. Paris: INSERM, 1982.

HERZLICH, Claudine. Médécine moderne et quête de sens: la maladie signifiant social. In: AUGÉ, Marc; HERZLICH, Claudine. (Org.). Le sens du mal, anthropologie, histoire, sociologie de la maladie. Paris: Archives Contemporaines, 1984.

KUHN, Thomas. A estrutura das Revoluções Científicas. São Paulo: Ed. Perspectiva, 2006.

LATOUR, Bruno. La science en action. Paris: Pandore, 1990.

LATOUR, Bruno. On technical mediation - philosophy, sociology, genealogy. Common Knowledge, Duke University Press, v. 3, n. 2, p. 29-64, 1994.

LEMOS, Vinícius. ‘Ele está incentivando a baderna': o desabafo de enfermeira após Bolsonaro pedir que seguidores invadam 
Necropolítica, poder e significados da pandemia do coronavírus: uma abordagem antropológica Jaqueline Ferreira

hospitais. BBC NEWS. São Paulo, 12 de junho de 2020. Disponível em: https://www.bbc.com/portuguese/brasil-53030520. Acesso em: 03 jan. 2021.

LINDENBAUM, Shirley, LOCK, Margaret (Org). Knowledge Power and Practice: The Anthropology of Medicine and Everyday Life. Berkeley: Califórnia, University of California Press, 1993.

LIRA E SILVA, Daiana Beatriz et al. Retrospectiva histórica do Coronavírus COVID-19. In: ARRUDA, Aurilene; LIRA e SILVA, Daiana Beatriz. Construção do Saber sobre COVID-19. João Pessoa: Editora do CCTA, 2020, p.21-37.

MARTIN, Emily. Flexible Bodies: Tracking Immunity In American Culture from the Days of Polio to the Age of AIDS. Boston: Beacon Press, 1994.

MARTINS, Roberto de Andrade et al. Contágio: história da presença das doenças transmissíveis. São Paulo: Editora Moderna, 1997.

MALUF, Sonia. Antropologia em tempo real: urgências etnográficas na pandemia. Florianópolis, UFSC INCT Brasil Plural. Disponível em: https://brasilplural.paginas.ufsc.br/antropologia-na-pandemia/antropologia-em-tempo-real-urgencias-etnograficas-na-pandemia/. Acesso em: 16 out. 2020.

MBEMBE, Achille. Necropolítica. Revista do Programa de PósGraduação em Artes Visuais/EBA/UFRJ, ano XXII, n. 32, p. 123151,2016

MINAYO, Maria Cecília S. O desafio do conhecimento: pesquisa qualitativa em saúde. São Paulo: Hucitec, 2010a.

MINAYO, Maria Cecília S. (org.). Pesquisa social: teoria, método e criatividade. Petrópolis: Vozes, 2010b.

NASCIMENTO, Giogia Carolina. A vida e a morte entre o gestar e o respirar: mortalidade materna por COVID-19. Espiritualidade Institucionalizada. Net, Campinas, 18 set. 2020. Disponível em: 
Necropolítica, poder e significados da pandemia do coronavírus: uma abordagem antropológica Jaqueline Ferreira

https://nues.com.br/a-vida-e-a-morte-entre-gestar-e-respirar/?fbclid=IWAR195JOK58vSBZhlmr2dlaABzNcFY2zDlauQNMvufejdyZGUSIDTY6CI96U. Acesso em: 07 out. 2020.

\section{NATIVIDADE, Priscila. Dá para pegar coronavírus em casa?}

Cuidado com as sacolas de plástico. CORREIO (Bahia). Salvador, 23 maio de 2020. Disponível em: https://www.correio24horas. com.br/noticia/nid/da-para-pegar-coronavirus-em-casa-cuidadocom-as-sacolas-de-plastico/ Acesso: 17 out. 2020.

NOIS (Núcleo de Operações e Inteligência em Saúde). Nota técnica 7: Análise da subnotificação do número de casos confirmados da Covid-19 no Brasil, 11 de abril de 2020. Disponível em: https:// drive.google.com/file/d/1_whlqZnGgvqHuWCG4-JyiL2X9WXpZAe3/ view Acesso em: 03 jan. 2021.

\section{NICOLAV, V. O que passou na "boiada" de Ricardo Salles} durante a pandemia? Brasil de Fato, 09 de junho de 2020. Disponível em: https://www.brasildefato.com.br/2020/06/09/oque-passou-na-boiada-de-ricardo-salles-durante-a-pandemia. Acesso em: 12 jun. 2020.

OLIVEIRA, Denise Cristina. Análise de conteúdo temático-categorial: uma proposta de sistematização. Revista Enfermagem, Rio de Janeiro, v. 16, n. 4. p. 569-576, 2008.

OLIVEIRA, Roberta Gondim de et al. Desigualdades raciais e a morte como horizonte: considerações sobre a COVID-19 e o racismo estrutural. Cad. Saúde Pública, Fiocruz, vol. 36, n. 9, p. 1-14, 2020.

GARCIA, Leila Posenato. Uso de máscara facial para limitar a transmissão da COVID-19. Epidemiol. Serv. Saúde, Brasília, vol. 29, n. 2, p. 1-4, 2020.

REZENDE, Cláudia. Reflexões sobre o constrangimento e o medo na pandemia. DILEMAS: Revista de Estudos de Conflito e Controle Social, Rio de Janeiro, Reflexões na Pandemia. 10 de julho de 2020, p. 1-5. 
Necropolítica, poder e significados da pandemia do coronavírus: uma abordagem antropológica Jaqueline Ferreira

RODRIGUES, Carla. Por uma filosofia política do luto. O que nos faz pensar, Rio de Janeiro, v. 29, n. 46, p. 58-73, jan./jun. 2020.

SANTOS, Márcia Pereira Alves dos et al. População negra e Covid-19: reflexões sobre racismo e saúde. Revista Estud. Av., São Paulo, vol. 34, n. 99, p. 225-244, 2020.

SEGATA, Jean. O novo normal é o nosso pesadelo. Jean Segata entrevistado por Marcos Weissheimer. Net. Porto Alegre. Outras Mídias. 01 de outubro de 2020. Disponível em: https://outraspalavras.net/outrasmidias/o-novo-normal-e-o-nosso-pesadelo/?fbclid=IwAR0puUDvA5wjI5XVdL9TUUNHcc5dCvb7w2zBlcah2qptpyHRCtJvEuHtKUI. Acesso em: 14 out. 2020.

SOUZA, Thais; NASCIMENTO, Rafael Souza. Prefeitura decide não multar casal que discutiu com fiscais; especialistas avaliam conduta em bar da Barra da Tijuca. Jornal Extra. Rio de Janeiro, julho de 2020. Disponível em: https://extra.globo. com/noticias/rio/prefeitura-decide-nao-multar-casal-que-discutiu-com-fiscais-especialistas-avaliam-conduta-em-bar-da-barra-da-tijuca-24521128.html Acesso em: 18 out. 2020.

TAKEMOTO, Maira L. S. et al. The tragedy of COVID-19 in Brazil: 124 maternal deaths and counting. International Journal of Gynecology and Obstetrics, vol. 151, n. 1, p. 154-156, jul. 2020. VARGAS, Mateus. Bolsonaro sobre atraso de dados oficiais do coronavírus: "Acabou matéria do Jornal Nacional". GZH POLÍTICA. Porto Alegre, 05 de junho de 2020. Disponível em: https://gauchazh.clicrbs.com.br/politica/noticia/2020/06/bolsonaro-sobre-atraso-de-dados-oficiais-do-coronavirus-acabou-materia-no-jornal-nacional-ckb2ujoxq006k015n3oput0sh.html. Acesso em: 03 jan. 2021.

VICK, Mariana. Como a pandemia agrava o risco de invasões em terras indígenas. Nexo. São Paulo, 18 de abril de 2020. Disponível em: https://www.nexojornal.com.br/ expresso/2020/04/18/Como-a-pandemia-agrava-o-risco-de- 
Necropolítica, poder e significados da pandemia do coronavírus: uma abordagem antropológica Jaqueline Ferreira

invas\%C3\%B5es-em-terras-ind\%C3\%ADgenas. Acesso em: 10 out. 2020.

VIEIRA, Antônio Otaviano. O direito de fala e de memória na epidemia. Cientistas Sociais e o Coronavirus. ANPOCS, Boletim Especial,São Paulo, n. 30, p. 1-6 abr. 2020.

VIGARELLO, Georges. O limpo e o sujo, uma história da higiene corporal. São Paulo: Martíns Fontes, 1996.

WIKIPEDIA. Template covid-19 pandemic data/brasil med-

ical cases. Disponível em: https://en.wikipedia.org/wiki/

Template:COVID-19_pandemic_data/Brazil_medical_cases. Acesso em: 15 out. 2020.

\section{7}

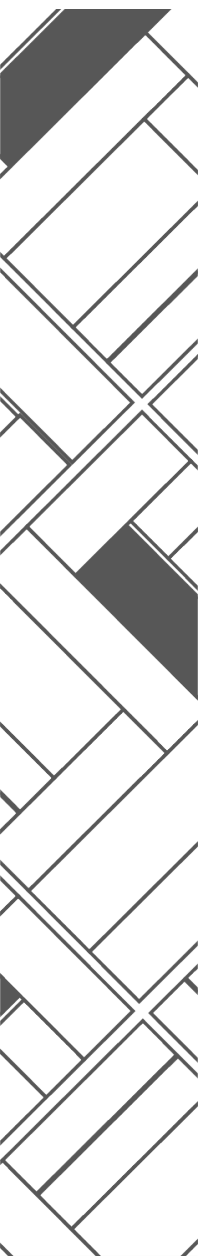

